ECONOMICS

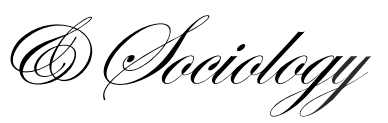

\author{
Dalia Streimikiene, \\ Vilnius University, \\ Kaunas, Lithuania, \\ E-mail: \\ dalia.streimikiene@kkhf.vu.lt \\ Tomas Baležentis, \\ Lithuanian Institute of Agrarian \\ Economics, \\ Vilnius, Lithuania, \\ E-mail:tomas@laei.lt
}

Irena Kriščiukaitienè, Lithuanian Institute of Agrarian

Economics,

Vilnius, Lithuania

Received: December, 2015

1st Revision: January, 2016

Accepted: February, 2016

DOI: $10.14254 / 2071-$

789X.2016/9-1/4

JEL Classification: C44, Q12
Streimikiene, D., Baležentis, T., Kriščiukaitienè, I. (2016), Benefit of the Doubt Model for Financial Risk Analysis of Lithuanian Family Farms, Economics and Sociology, Vol. 9, No 1, pp. 60-68. DOI: 10.14254/2071-789X.2016/9-1/4

\section{BENEFIT OF THE DOUBT MODEL FOR FINANCIAL RISK ANALYSIS OF LITHUANIAN FAMILY FARMS}

\begin{abstract}
The aim of this research is to propose a methodology for integrated assessment of financial risks of family farms in Lithuania. The methodology is based on the benefit of the doubt model. The research relies on the farm-level data from Farm Accountancy Data Network and covers the period of 2004-2011. Multiple financial indicators are included in the model to encompass such features as returns, capital structure, cost of capital, and cash flows. The research focuses on the four main types of farming prevailing in Lithuania, viz. cereal farming, general field cropping, dairying, and mixed field crops - grazing livestock farming. The results show that the financial risk generally increased in Lithuanian family farms during 2004-2011. However, a rebound has been observed in the period since 2009. This might be related to investment decisions and subsequent modernisation. Cereal farms face the highest financial risk, whereas dairy farms are the least exposed to them.
\end{abstract}

\title{
Introduction
}

Agricultural activities differ from other businesses in that the former are subject to much wider range of risks. Specifically, besides commonly known input and output price risk, credit risk, institutional risk etc., farmers are exposed to risks emerging from changes in biophysical environment. Therefore, it is important to foresee the sources of risk, farmers' strategies, and government policies (OECD, 2009). An appropriate interaction among these components of risk management strategy might mitigate loss due to different types of risks.

Risk management is of especial importance in the new European Union (EU) Member States, where agricultural sector has been experiencing serious economic, institutional, and social transformations since the 1990s. Indeed, the collapse of planned economy including large-scale collective farming systems induced certain volatility in factor markets and resulted in sub-optimal farming structure in some cases (Bilan \& Chmielewska, 2013a,b). Furthermore, accession to the EU allowed receive the funding under the Common Agricultural Policy (Ministry of Agriculture of the Republic of Lithuania, 2015). The latter has been distributed in the form of both direct payments and investment subsidies. 
Demographic transition implies a decreasing labour supply in rural areas and thus calls for further mechanisation.

According to to R. B. M. Huirne et al. (2000) and J. B. Hardaker et al. (2004) there are two broad categories of risk for agricultural activities, viz. business risk and financial risk. Business risk comprises production, market, institutional, and personal risks (Bernat et al. 2014). Financial risk stems from fluctuations at financial markets and farmers' moneyrelated decisions. Specifically, increasing interest rates might render difficulties in repaying loans or create credit constraints. Farmers' decisions regarding capital structure might also impact the financial viability of farms.

As regards the agricultural sector, much of literature has been focused on business risk and, particularly, risk aversion (e.g., Moschini, Hennessy, 2001). The estimation of risk aversion can follow either the attitudinal approach, or empirical approach. The attitudinal approach relies on questionnaire surveys or experiments aimed at identifying farmers' choices under different circumstances. The empirical approach relies on the analysis of factual data and can be carried out either parametrically (Bardsley, Harris, 1987; Bar-Shira et al., 1997) or nonparametrically (Gomez-Limon et al., 2003). The analysis of financial risk has been confined to estimation the impacts of certain financial ratios on probability to become unviable (Argiles, 2001). Such a framework rests on the ideas of Altman (1968, 2004). However, such a setting requires a priori specification of the dependent variable, which involves a certain degree of subjectivity. D. Jackson-Smith et al. (2004) and S. Davidova and L. Latruffe (2007) investigated the determinants of financial performance treating different indicators as dependent variables in regression models. However, no aggregate measures were introduced.

In Lithuania, as well as in other Central and East European countries, financial risk constitutes an important dimension of farm viability due to investments in response to the aforementioned transformations there. First, excessive investments might be fuelled by investment support measures thus arriving at unreasonable leverage level. Second, credit constraints might be related to increase in interest rates. Therefore, it is important to offer appropriate methodologies for financial risk appraisal in Lithuanian family farms. The following scientific problem, therefore, emerges: even though a variety of techniques for analysis of financial risk are available, these usually require longitudinal data for estimation of variance; however, such data are not readily available for Lithuanian family farms where extensive time series are not available for multiple holdings. Accordingly, there is a need for additional techniques, which could support decision making, based upon accounting data without long record history.

This paper, thus, proposes a methodology for integrated assessment of financial risks at family farms. The methodology is based on frontier technique, viz. Data Envelopment Analysis (Farrell, 1957; Charnes et al., 1978). Given the model aims at aggregating multiple financial indicators, the benefit of the doubt model is employed for the analysis (Cherchye et al., 2007; Rogge, 2011). The latter approach entails relative measures of financial risk and allows identifying weaknesses and strengths for the units assessed without imposing restrictive assumptions regarding the importance of different financial indicators. The research relies on farm-level data from Farm Accountancy Data Network (FADN) and covers the period of 2004-2011.

\section{Preliminaries}

\subsection{The benefit of the doubt model}

Construction of composite indicators usually involves the two critical stages, viz. normalisation and weighting. The benefit of the doubt model solves these issues by assigning 
the most preferable weight for each observation. These weights, therefore, allow both normalising the data and ensuring objective weighting. The use of term "objective" here means that the model involves no subjectivity arising from such techniques as expert assessments etc. Indeed, the weights are endogenously determined to ensure that only farms with the same weighting vectors can be compared. This allows for different strategies towards financial risk mitigation.

Mathematically, the benefit of the doubt model can be given as a linear programming problem (Cherchye et al., 2007). Assume that $j=1,2, \ldots, n$ is the index of farms and $i=1,2, \ldots, m$ is the index of indicators analysed. All the indicators, $y_{j, i}$, are to be maximised. In our case, the higher value of the composite risk score is related to lower financial risk. Without loss of generality, a certain farm is picked from the sample, $c=1,2, \ldots, n$. The risk score is then estimated as

$$
\begin{aligned}
& R_{c}=\max _{w_{c, i}} \sum_{i=1}^{m} w_{c, i} y_{c, i} \\
& \text { s.t. } \\
& \sum_{i=1}^{m} w_{c, i} y_{j, i} \leq 1, j=1,2, \ldots, n \\
& w_{c, i} \geq 0, i=1,2, \ldots, m
\end{aligned}
$$

where $w_{c, i}$ is the weight of the $i$-th indicator. The model can be implemented as an inputoriented Data Envelopment Analysis model (Charnes et al., 1978) with the same input level (e.g., unity) for all observations.

The benefit of the doubt model presented in Eq. 1 allows identifying the relative importance of different indicators for each particular observation. Specifically, the risk score can be decomposed into products of weights and values of individual indicators. In order to account for the level of risk, as expressed by the risk score, these products are normalised by sum thereof (i.e., risk score):

$$
\omega_{c, i}=w_{c, i}^{*} y_{c, i} / R_{c},
$$

where $w_{c, i}^{*}$ solves Eq. 1 and $\omega_{c, i}$ is the normalised weight. The resulting variables show the relative contribution of each indicator towards the overall risk score. Indeed, higher values indicate that a certain farm maintains lower exposure to financial risk if opposed to others in a certain dimension.

\subsection{Financial ratios}

In order to estimate the financial risk in Lithuanian family farms, an indicator system has been proposed in lines with J. M. Argilés (2001), S. Davidova and L. Latruffe (2007), L. Girdziute et al. (2014) and L. C. Hsu (2015). Specifically, the indicators considered encompass such features as returns, capital structure, cost of capital, and cash flows. Therefore, farms are compared among themselves in terms of their exposure towards financial risk.

The following indicators are included in the model:

1. Returns on Assets capture farm productivity and is measured as a ratio of total agricultural output (in Euro) to total assets (at the end of the year).

2. Inverse of Debt to Assets ratio measures the financial leverage of the farm. 
3. Current ratio is measured as a ratio of current assets (non-breeding livestock, stocks of agricultural products, and other circulating capital) to current liabilities (at the end of the year) and represents the liquidity of the farm.

4. Cash flow ratio is measured as a ratio of revenue from marketed output over the current liabilities (at the end of the year) and identifies farm's viability in terms of the cash flow.

5. Inverse of a ratio of wages and salaries, rentals, and interests to the total agricultural output identifies farm's dependence upon external production factors.

The proposed indicator system, thus, enables to identify financial risk stemming from both long- and short-term financial management decisions as well as changes in the environment a farm operates in. note that some of the variables are inverted so that the higher values of the resulting risk scores would indicate lower financial risk, as measured by the aggregate score (Eq. 1).

\subsection{Data used}

The research focuses on the four main types of farming prevailing in Lithuania, viz. cereal farming (type 15 under regulation 1242/2008 EC; type 13 under regulation 2003/369 EC), general field cropping (type 16; type 14), dairying (type 45; type 41), and mixed field crops - grazing livestock farming (type 83; type 81).

Table 1 . The numbers of Lithuanian family farms analysed across farming types and time periods

\begin{tabular}{lrrrrrrrrr}
\hline \multicolumn{1}{c}{ Farmingtype } & 2004 & 2005 & 2006 & 2007 & 2008 & 2009 & 2010 & 2011 & Total \\
\hline Cereal (15) & 350 & 291 & 315 & 330 & 359 & 292 & 302 & 264 & 2503 \\
\hline Fieldcropping (16) & 149 & 142 & 125 & 122 & 86 & 122 & 76 & 105 & 927 \\
\hline Dairying (45) & 126 & 103 & 78 & 108 & 129 & 111 & 205 & 214 & 1074 \\
\hline Mixed (83) & 83 & 108 & 94 & 93 & 102 & 120 & 104 & 115 & 819 \\
\hline Total & 708 & 644 & 612 & 653 & 676 & 645 & 687 & 698 & 5323 \\
\hline
\end{tabular}

Source: own calculation.

Farms with current or total liabilities less than 200 EUR were not considered in the analysis. The same applies for cost of external factors. Indeed, such farms might be treated as facing no serious financial risk as they are not strongly linked to the financial markets. The resulting number of observations is decomposed in Table 1.

\section{Results}

The differences in financial ratios, related to financial risk, across farming types were identified by the means of Least Significant Difference (LSD) test at the level of significance of 5\%. As Table 2 suggests, cereal and field cropping farms (types 15 and 16) feature the highest level of returns on assets. The remaining farming types are significantly different in terms of the mean rate of returns. The inverse of debt to assets ratio indicates that cereal and field crop farms are specific with the highest financial leverage ratio (the difference from the other farming types is significant). Dairy and mixed farms (types 45 and 83) show significantly higher values of current ratio and cash flow indicator. Dairy farms are least dependent on external factors, as suggested by the corresponding ratio. Field cropping and dairying maintain the same level of dependence on external factors. In the sequel, the benefit 
of the doubt model will be applied to aggregate these indicators into a composite financial risk score.

Table 2. Mean values of financial ratios

\begin{tabular}{lccccc}
\hline \multicolumn{1}{c}{ Farmingtype } & 1 & 2 & 3 & 4 & 5 \\
\hline Cereal (15) & $0.42^{\mathrm{a}}$ & $10^{\mathrm{c}}$ & $9^{\mathrm{c}}$ & $7^{\mathrm{c}}$ & $15^{\mathrm{c}}$ \\
\hline Fieldcropping (16) & $0.41^{\mathrm{a}}$ & $13^{\mathrm{b}}$ & $9^{\mathrm{c}}$ & $8^{\mathrm{c}}$ & $20^{\mathrm{b}}$ \\
\hline Dairying (45) & $0.37^{\mathrm{b}}$ & $15^{\mathrm{a}}$ & $15^{\mathrm{a}}$ & $15^{\mathrm{a}}$ & $26^{\mathrm{a}}$ \\
\hline Mixed (83) & $0.35^{\mathrm{c}}$ & $15^{\mathrm{a}}$ & $13^{\mathrm{b}}$ & $11^{\mathrm{b}}$ & $21^{\mathrm{b}}$ \\
\hline
\end{tabular}

Source: own calculation.

Indicator numbers are the same as in Section 2.2.

Means with the same letter are not significantly different.

The data for each farming type were pooled over the years. Accordingly, the four "technologies" represented the performance of different farming types. Furthermore, a "metatechnology" was defined in the spirit of Charnes et al. (1981). The following setting allows one to analyse both managerial exposure to risk and program (farming type) risk. Specifically, managerial risk is relative to farming type frontier, whereas program risk is measured with respect to the meta-frontier. Accordingly, the three measures of risk are available: 1) managerial financial risk measures the risk of the farm with respect to other farms within the same farming type; 2) program financial risk measures the differences in risk among farming types with managerial risk being ignored; and 3) overall financial risk measures the financial risk of the farm with respect to the whole sample (i.e., all farming types are included) without ignoring managerial risk. These measures are estimated by the means of Eq. 1.

Looking at overall risk scores reveals that all the farming types show similar mean values and trends in financial risk (Fig. 1). The LSD test suggests that the mean risk scores do not differ significantly for general crop and mixed farms (types 16 and 83), whereas that for cereal farms (type 15) is significantly lower (at the level of significance of 5\%). Dairy farms (type 45) show the highest score, what indicates the lowest financial risk. Indeed, the mean values range in between 0.29 and 0.34. Obviously, years 2006 and 2009 mark a decrease in risk scores, which indicates an increasing exposure to financial risk. Indeed, these periods are related to negative changes in climatic conditions. As a result, financial risk increased during the said periods due to decreased output and revenue. The analysed farming types, though, differ in terms of the magnitude of temporal variation of the mean risk scores. The lowest values of the coefficient of variation (CV) are observed for dairying and general field cropping (0.09), whereas cereal and mixed farms feature CVs of 0.14.

During the period of 2004-2011, most of the analysed farming types faced a decrease in the overall financial risk scores, i.e., an increase in financial risk. As regards cereal farms (type 15), their mean overall financial risk score dropped from 0.35 down to 0.30 . Crop (type 16) and mixed (type 83) farms saw similar decreases. However, dairy farms (type 45) maintained virtually the same level of financial risk (0.37). 


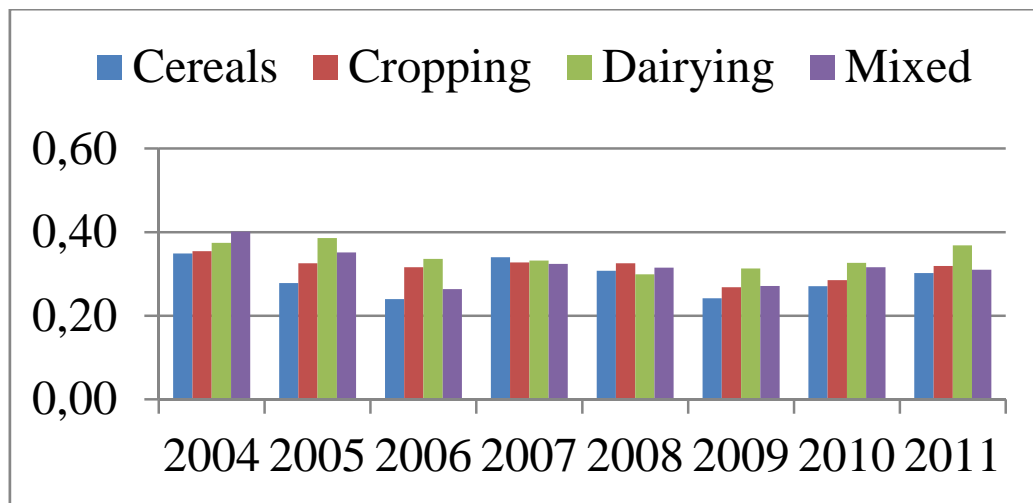

Fig. 1. Mean overall risk scores for different farming types (increasing values indicate a decrease in financial risk), 2004-2011

Source: own calculation.

Besides analysing overall risk scores, one can also consider managerial risk scores (Fig. 2). These are relative to farming type frontiers rather than the meta-frontier. The managerial risk scores are quite different across the farming types. This finding implies that there exist different degrees of heterogeneity in each farming type. This can be related to different practices of farming as well as risk mitigation strategies.

The highest mean managerial risk score of 0.50 is observed for mixed farms (type 83). Specialised crop and dairy farms (types 16 and 83) show rather similar mean managerial risk scores of 0.40 and 0.39 , respectively (these do not differ significantly according to the LSD test). Finally, cereal farms show the lowest mean managerial risk score (and, therefore, the highest managerial risk) of 0.31. The latter indicates that cereal farms are the most heterogeneous in terms of financial risk if opposed to the other farming types. The same trend is pertinent to all the farming types: decreases in financial risk scores are observed for years 2006 and 2009. In general, all the farming types saw a decrease in mean risk score during 2004-2011.

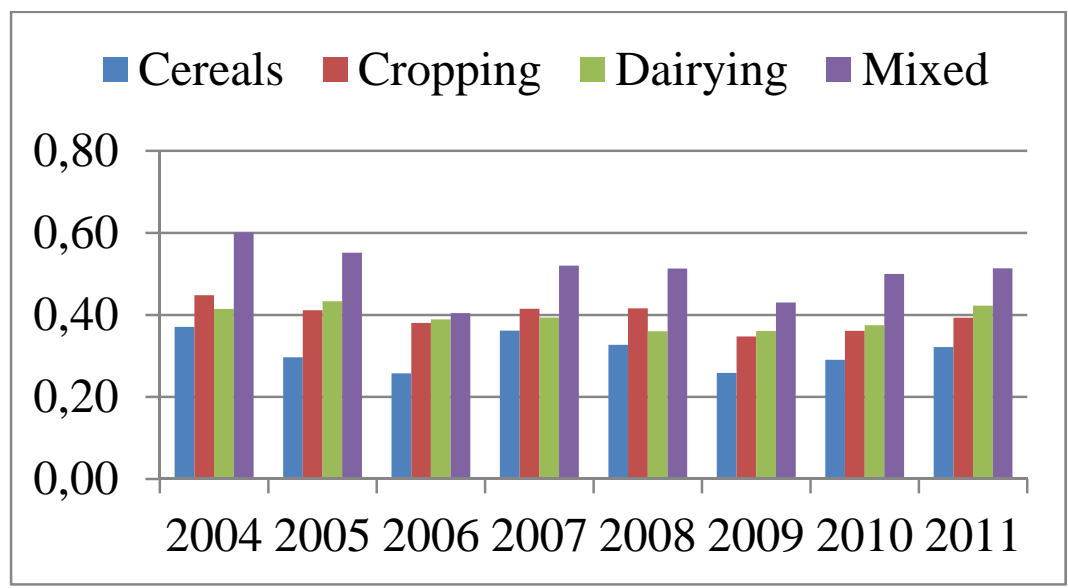

Fig. 2. Mean managerial risk scores for different farming types (increasing values indicate a decrease in financial risk), 2004-2011

Source: own calculation.

Program risk scores (Fig. 3) are time-invariant as both overall and managerial scores follow the same trend. Cereal farms reach the highest program efficiency equal to 0.94. This shows that cereal farms define the efficient frontier. However, due to the lowest managerial 
efficiency, most of these farms fall below the highest risk scores. General cropping and dairying are associated with medium level of the program financial risk scores (0.78 and 0.85, respectively). Mixed farms exhibit the lowest program financial risk score (0.62). Therefore, mixed farming is associated with the highest financial risk in general even though mixed farming should guarantee the opposite. A possible explanation is that mixed farming is unable to reach the productivity of specialised crop and livestock farms yet. Cereal farm, thus, emerge as the most attractive ones in terms of investment possibilities if financial risk is considered.

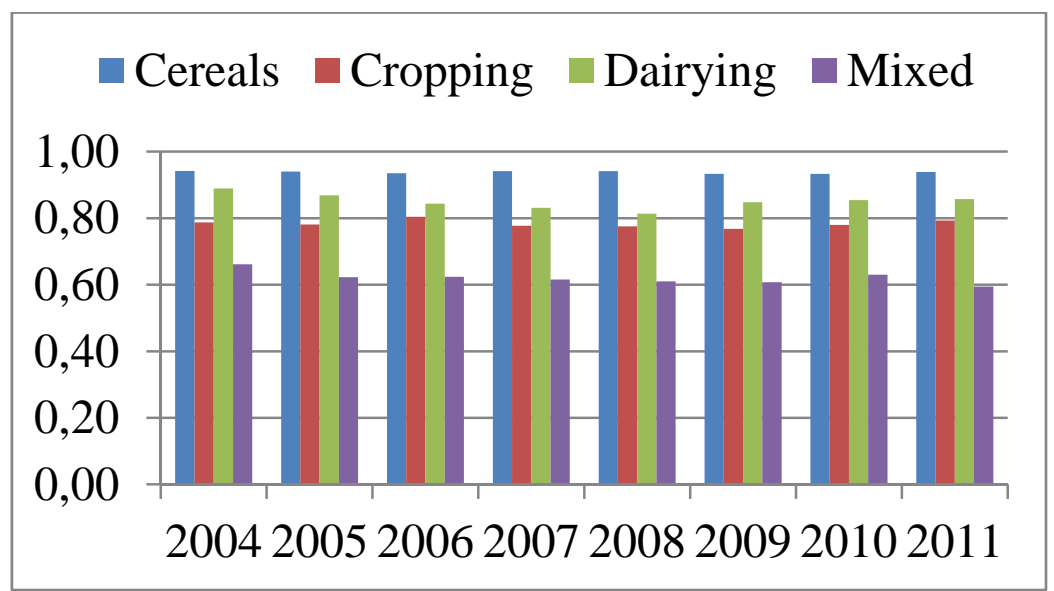

Fig. 3. Mean program risk scores for different farming types (increasing values indicate a decrease in financial risk), 2004-2011

To sum up, managerial risk is much higher across all the farming types if opposed to program financial risk. Accordingly, one might assume that farm-specific decisions play a more important role in risk management in Lithuanian family farms. Given overall financial risk scores are rather similar for different farming types, it can be asserted that managerial financial risk is the main cause of the overall financial risk for cereal farms. To put it otherwise, farm-specific factors entail higher risk levels there, even though the latter farming type allow achieving the lowest level of the financial risk.

As the benefit of the doubt model allows to identify the relative importance of different indicators for each particular observation, the mean values of the relative contribution of each indicator towards the overall risk scores can be analysed. Table 3 presents the average relative contributions of the financial ratios towards the overall risk scores. Note that the normalised weights are obtained by the virtue of Eq. 2.

Table 3. Normalised mean weights of the benefit of the doubt model

\begin{tabular}{lccccc}
\hline \multicolumn{1}{c}{ Type } & 1 & 2 & 3 & 4 & 5 \\
\hline Cereal (15) & 0.66 & 0.17 & 0.04 & 0.01 & 0.11 \\
\hline Fieldcropping (16) & 0.60 & 0.22 & 0.04 & 0.01 & 0.14 \\
\hline Dairying (45) & 0.53 & 0.22 & 0.07 & 0.02 & 0.15 \\
\hline Mixed (83) & 0.54 & 0.24 & 0.06 & 0.01 & 0.14 \\
\hline
\end{tabular}

Indicator numbers are the same as in Section 2.2.

As one can note from Table 3, returns on assets play the most important role in construction of the risk score. The highest importance is observed for crop and cereal farms, 
whereas dairy and mixed farms seem to be superior in other dimensions. Productive farms are less prone to maintaining low leverage ratios, sound monetary flows etc. Conversely, farms with worse financial ratios and high dependency on external factors are competing in terms of higher productivity of assets. These findings correspond to data in Table 2. Note that the weights vary across farms and time periods. Therefore, certain observations are attributed with weight vectors, which are different from the mean ones.

\section{Conclusions}

A methodology for analysis of financial risk in Lithuanian family farms has been proposed. The suggested approach encompasses multiple criteria, is objective in the sense of the importance of the underlying criteria, and requires no extensive time series data.

The results show that Lithuanian family farms have been facing an increasing financial risk during 2004-2011. However, a rebound has been observed for the period since 2009. This might be related to investment decisions and subsequent modernisation.

Cereal farms face the highest financial risk, whereas dairy farms are the least exposed. Nevertheless, the lowest program risk is observed for cereal farms. Therefore, these farms have the highest potential for risk reduction given the current situation in factor markets and agricultural support measures. Mixed farms show the highest program risk, which calls for further improvements in farm productivity and product mix. The results imply that such measures as state guarantee on borrowing should be applied with caution if the observed trends persist for cereal farms. On the other hand, crop insurance might be relevant to alleviate financial risk during unfavourable periods.

Analysis of the weights associated with different financial ratios implies that returns on assets was the most important indicator ensuring the most favourable scoring. Dairy and mixed farms seem to be better off in terms of financial indicators other than returns to assets.

In this paper, the variance of the financial indicators remained ignored as the analysis was carried out within separate time periods. Further studies, however, could attempt including the variance into analysis. Furthermore, the proposed indicator system can be developed to include different aspects of financial risk. Finally, more detailed studies could be carried out to identify farm-specific bottlenecks with respect to financial risk mitigation. Cluster analysis would be helpful in grouping farms in terms of their performance and risk level.

\section{References}

Altman, E. (1968), Financial ratios, discriminant analysis and the prediction of corporate bankruptcy, Journal of Finance, Vol. 23, No. 4, pp. 589-609.

Altman, E. (2004), Predicting corporate distress in a turbulent economic and regulatory environment, Rassegna Economica, Vol. 68, No. 2, pp. 483-524.

Argilés, J. M. (2001), Accounting information and the prediction of farm non-viability, European Accounting Review, Vol. 10, No. 1, pp. 73-105.

Bardsley, P., Harris, M. (1987), An approach to the econometric estimation of attitudes to risk in agriculture, Australian Journal of Agricultural Economics, Vol. 31, No. 02, pp. 112126.

Bar-Shira, Z., Just, R. E., Zilberman, D. (1997), Estimation of farmers' risk attitude: an econometric approach, Agricultural Economics, Vol. 17, pp. 211-222.

Bernat, T., Gasior, A., Korpysa, J., Lakomy-Zinowik, M., Nagaj, R., \& Szkudlarek, P. (2014), Perception of the Risk of Starting up Business and Personal Attitude to Risk. Transformations in Business \& Economics, 13(2B), 780-800 
Bilan, Y., Chmielewska, B. (2013a), Diversified Economic and Social Situation of Farms of the European Union as a Determinant of the Rural Areas Growth Policy, Actual Problems of Economics, 2 (10), pp. 213-221.

Bilan, Y., Chmielewska, B.(2013b), Strategic challenge for farming and rural areas in relation to small and semi-subsistence farms, Actual Problems of Economics, 2 (1-2), pp. 116124.

Charnes, A., Cooper, W. W., Rhodes, E. (1981), Evaluating program and managerial efficiency: an application of data envelopment analysis to program follow through, Management Science, Vol. 27, No. 6, pp. 668-697.

Charnes, A., Cooper, W. W., Rhodes, E. (1978), Measuring the efficiency of decision making units, European Journal of Operational Research, Vol. 2, No. 6, pp. 429-444.

Cherchye, L., Moesen, W., Rogge, N., van Puyenbroeck, T. (2007), An introduction to 'benefit of the doubt' composite indicators, Social Indicators Research, Vol. 82, pp. 111-145.

Davidova, S., Latruffe, L. (2007), Relationships between technical efficiency and financial management for Czech Republic farms, Journal of Agricultural Economics, Vol. 58, No. 2, pp. 269-288.

Farrell, M. J. (1957), The measurement of technical efficiency, Journal of the Royal Statistical Society, Series A, General, Vol. 120, No. 3, pp. 253-281.

Gomez-Limon, J. A., Arriaza, M., Riesgo, L. (2003), An MCDM analysis of agricultural risk aversion, European Journal of Operational Research, Vol. 151, pp. 569-585.

Girdziute, L., Slavickiene, A., \& Vaitkevicius, S. (2014), Integrated Risk Assessment at Lithuanian Farms. Transformations in Business \& Economics, 13(1), 143-154

Hardaker, J. B., Huirne, R., Anderson, J. R., Lien, G. (2004), Coping with Risk in Agriculture, CABI Publishing.

Hsu, L. C. (2015), Using a decision-making process to evaluate efficiency and operating performance for listed semiconductor companies, Technological and Economic Development of Economy, Vol. 21, No. 2, pp. 301-331.

Huirne, R. B. M., Meuwissen, M., Hardacker, J. B., Anderson, J. R. (2000), Risk and risk management in agriculture: an overview and empirical results, International Journal of Risk Assessment and Management, Vol. 1, pp. 125-136.

Jackson-Smith, D., Trechter, D., Splett, N. (2004), The contribution of financial management training and knowledge to dairy farm financial performance, Applied Economic Perspectives and Policy, 26(1), pp. 132-147.

Ministry of Agriculture of the Republic of Lithuania (2015), Rural Development Programme for Lithuania 2007-2013.

Moschini, G., Hennessy, D. A. (2001), Uncertainty, risk aversion, and risk management for agricultural producers, Handbook of Agricultural Economics, Vol. 1, pp. 88-153.

OECD (2009), Managing Risk in Agriculture: A Holistic Approach, Paris: OECD.

Rogge, N. (2011), Granting teachers the "benefit of the doubt" in performance evaluations, International Journal of Educational Management, Vol. 25, No. 6, pp. 590-614. 